\title{
$=\mathrm{T} R A M A=$
}

\section{A (RES)SIGNIFICAÇÃO DO ENSINO DE LÍNGUA MATERNA PROPICIADA POR NARRATIVAS DE VIDA PRODUZIDAS EM ESTÁGIO DE OBSERVAÇÃO NO CONTEXTO PANDÊMICO}

\author{
FRANCISCO ROGIELLYSON DA SILVA ANDRADE (UFC) ${ }^{1}$ \\ https://orcid.org/0000-0002-2585-1878 \\ EDLA FREITAS RIBEIRO (URCA) \\ https://orcid.org/0000-0001-6504-0722 \\ SANDRA MAIA FARIAS VASCONCELOS (UFC) $)^{3}$ \\ https://orcid.org/0000-0001-7201-6173
}

\begin{abstract}
RESUMO: Sob o viés metodológico da etnossociologia clínica (ANDRADE, 2019), este artigo analisa narrativas de vida coletadas em uma disciplina de estágio de observação do curso de Letras: Língua Portuguesa da Universidade Federal do Ceará. Em vista da impossibilidade das aulas presenciais, por conta da pandemia de Covid-19, as práticas de formação docente tiveram que ser repensadas. Nesse contexto, as narrativas de vida surgem como catalisadoras de experiências, permitindo ao professor em formação reconfigurar saberes e conhecimentos adquiridos em seu itinerário, (res)significando concepções de linguagem. Assim, as narrativas de vida podem se tornar um produtivo meio de prática (auto)(trans)formativa. O estudo se abaliza nos postulados teóricos de Koch (2013), Geraldi (2011) e Volóchinov (2018) sobre concepções de linguagem, e em Andrade, Lima e Serra (2020a, 2020b), Kleiman (2008), Josso (2004), Ribeiro (2008), Signorini (2006) e Delory-Momberger (2008) sobre a possibilidade (auto)(trans)formativa das narrativas de vida. Os resultados apontam que os professores em formação afirmam ter experienciado o ensino de língua sob o prisma da linguagem como expressão do pensamento e/ou instrumento de comunicação, desejando, por isso, quando em exercício de sua docência, efetivarem práticas mais afeitas à perspectiva sociointeracional, utilizando o potencial reflexivo dos planos de aula, amparados na metodologia sequência didática.
\end{abstract}

PALAVRAS-CHAVE: Narrativa de vida. Prática (auto)(trans)formativa. Formação docente. Pandemia.

\section{THE (RE)SIGNIFICANCE OF MOTHER-TONGUE TEACHING PROVIDED BY NARRATIVES OF LIFE PRODUCED AT THE OBSERVATION STAGE IN THE PANDEMIC CONTEXT}

\footnotetext{
${ }^{1}$ Mestre e doutorando em Linguística pelo Programa de Pós-Graduação em Linguística da Universidade Federal do Ceará, Graduado em Letras: Língua Portuguesa e respectivas Literaturas de Língua Portuguesa pela Universidade Federal do Ceará e Especialista em Língua Portuguesa e Literatura Brasileira pela Universidade Cândido Mendes. E-mail: rogiellyson@yahoo.com.br

${ }^{2}$ Mestranda em Letras pelo PPGL da Universidade Regional do Cariri. Formada em Letras pela Universidade Regional do Cariri-URCA e em Jornalismo pela Universidade Federal do Cariri-UFCA. E-mail: edla.fribeiro@urca.br

${ }^{3}$ Docente do Departamento de Letras Vernáculas da Universidade Federal do Ceará. Doutora em Sciences de L'Education pela Universidade de Nantes e Pós-Doutora pela Universidade Federal do Rio Grande do Norte. Email: sandramaiafv@gmail.com 


\section{$=$ TRAMA $=$}

ABSTRACT: Under the methodological bias of clinical ethnosciology (ANDRADE, 2019), this article analyzes life narratives collected in an observation internship course of Languages: Portuguese of the Federal University of Ceará. In view of the impossibility of presential classes, due to the Covid-19 pandemic, teaching practices had to be rethought. In this context, life narratives emerge as catalysts of experiences, allowing the teacher in training to reconfigure knowledge and knowledge acquired in his itinerary, (re)signifying conceptions of language. Thus, life narratives can become a productive means of (self)(trans)formative practice. The study is based on theoretical postulates Koch (2013), Geraldi (2011) and Volóchinov (2018) on conceptions of language, and Andrade, Lima and Serra (2020a, 2020b), Kleiman (2008), Josso (2004), Ribeiro (2008), Signorini (2006) e DeloryMomberger (2008) on the (self)(trans)formative possibility of life narratives. The results show that teachers in training affirm to have experienced language teaching from the perspective of language as an expression of thought and/or as an instrument of communication, and therefore wish, when teaching, to carry out practices that are more affected by the socio-international perspective, using the reflexive potential of lesson plans, supported by the methodology of didactic sequence.

KEYWORDS: Narrative of life. Formative (self)(trans)practice. Teacher training. Pandemic.

\section{INTRODUÇÃO}

A narrativa de vida é uma modalidade de escrita que tem se desenvolvido ao longo dos anos. Aqui, estudaremos a narrativa de formação, um dos vieses da narrativa de vida. Para Delory-Momberger (2008, p. 36), quando um sujeito narra sua vida, verdadeiramente, apropriase dela, pois a escrita de um vivido coloca sua vida na linguagem das histórias. Por meio da narrativa, atribui-se valor a pessoas, situações, acontecimentos e relações. O viver pessoal é enriquecido quando se observam os trajetos percorridos, numa tomada consciente dos desdobramentos de suas ações e percepções.

Também, por intermédio da vida narrada, constituem-se materialidades que oferecem testemunho sobre o modo e as condições sobre as quais os sujeitos contam sua época, descrevem grupos sociais em que circulam e a que forma de cultura estão associados. $O$ vínculo com o próprio saber ganha, igualmente, destaque nesse exame de si na produção narrativa de si mesmo. Este é um tipo de conhecimento que permite ao sujeito que as experiências adquiridas se tornem contribuidoras diretas no processo de aquisição de novos conhecimentos (JOSSO, 2004).

Para Silva (1999), a forma como se experienciam as práticas sociais influenciam na elaboração de crenças e concepções que se fazem delas. Por isso, o estágio de observação é crucial na formação inicial docente, porque, por meio dessa prática, analisa-se como o ensino se dá em um contexto real e posiciona-se frente à realidade existente, (re)pensando sobre o exercício da docência.

Em 2020, porém, a pandemia de Covid-19 redimensionou as práticas de formação a que estávamos acostumados. Foi preciso repensar metodologias que garantissem a qualidade dos estágios, mesmo que os professores em formação não pudessem, como de costume, assistir a aulas em seu contexto real de existência.

Para superar essa dificuldade, coadunando com os achados de Andrade, Lima e Serra (2020a, 2020b), percebemos que, no contexto de estágio de observação, as narrativas de vida são materialidades enunciativas que permitem o sujeito narrador catalisar suas experiências, apresentando uma análise acerca delas e se posicionando, ora aproximando-se, ora afastandose das concepções que emergem dessa avaliação propiciada pelas materialidades narrativas. Ou seja, o ato de narrar-se constitui um referencial que serve de apoio ao sujeito na verificação de circunstâncias anteriormente inéditas. Através da narrativa, conectam-se experiências 


\section{$=$ TRAMA $=$}

vividas nos bancos escolares com o percurso formativo docente, possibilitando, assim, outros modos de mediação de conhecimento.

Sob esse prisma, neste artigo, analisamos a (res)significação de concepções de linguagem propiciada por narrativas de vida escritas em função do Estágio em Oralidade, Escrita e Análise Linguística, disciplina obrigatória da licenciatura em Letras: Língua Portuguesa - LLP da Universidade Federal do Ceará - UFC. Para isso, o texto se organiza assim: afora introdução e conclusão, a seguir, apresentamos as principais concepções de linguagem que podem emergir das experiências de ensino; após, discutimos como as narrativas de vida podem vigorar como prática (auto)(trans)formativa. Em seguida, detalhamos os passos metodológicos que nos permitiram coleta e análise dos dados. Por fim, apresentamos nossas considerações analíticas, discutindo como as narrativas puderam catalisar crenças que foram (res)significadas pelos professores em formação.

\section{CONCEPÇÕES DE LINGUAGEM}

Koch (2013) afirma que a linguagem, ao longo do tempo, tem sido concebida de diferentes maneiras. Nessa conjuntura em que diferentes crenças podem ser percebidas, um conceito tão complexo como o de linguagem deve ser pensado sob o prisma das singularidades efetivadas pelas circunstâncias interativas que lhe circunscrevem. Koch (2013), nessa medida, afirma que a História percebeu a linguagem sob o prisma de três invariantes categoriais:

a) Expressão do pensamento: a linguagem seria, nessa orientação, espelho do pensamento.

b) Instrumento de comunicação: a linguagem seria o dispositivo pelo qual o emissor envia mensagens ao ouvinte.

c) Lugar de interação: a linguagem seria a instância geradora da interação, evento único e irrepetível em função do qual os sujeitos, num enquadre sócio-históricocultural mediato e imediato, posicionam-se frente à realidade, elaborando-a.

Geraldi (2011), afirma que, a cada uma dessas concepções, corresponde determinada abordagem de ensino. Ao pensar-se a linguagem sob o prisma da expressão do pensamento, segundo aquele autor, seria tarefa do ensino trabalhar a prescrição gramatical, sendo a língua uma norma; aqueles sujeitos que não conseguem se adequar a esse regime teriam um pensamento caótico, desorganizado. Seria tarefa do professor, então, transmitir aos estudantes as regras do bem falar e escrever, em conformidade com o que é prescrito pela norma-padrão, por meio de atividades de repetição.

Sob a lente da linguagem como instrumento de comunicação, a tarefa do ensino é ensinar composição, ou seja, tipologias textuais, a fim de que os estudantes aprendam a como formatar suas mensagens no enquadre prototípico das sequências textuais. Assim, a língua é um instrumento que permite as mensagens do emissor chegarem ao ouvinte, de modo que não há uma constituição histórico-cultural que medeia essa interação, pois a comunicação é vista como linear.

Por fim, entendendo a linguagem como lugar de interação, ainda segundo a teorização de Geraldi (2011), o papel do ensino é analisar as operações que o sujeito deve empreender por meio dos textos. Assim, todo enunciado, como teoriza Volóchinov (2018), é uma unidade reveladora de uma posição valorativa do enunciador, circunscrita a aspectos históricos, sociais, culturais. Ainda, o(s) interlocutor(es) é/são alguém em função de quem o texto se organiza. Do mesmo modo, o gênero discursivo que enquadra o enunciado é um material analítico do ensino, pois é ele que permite o funcionamento da linguagem conforme objetivos responsivamente projetados pelos interlocutores. 


\section{$=$ TRAMA $=$}

No bojo desses prismas sob os quais podem ser entrevistos linguagem e seu ensino, podemos fazer a seguinte síntese:

Quadro 1: Concepções de linguagem e suas abordagens inerentes sobre ensino

\begin{tabular}{|c|c|c|c|}
\hline $\begin{array}{c}\text { Concepção de } \\
\text { linguagem }\end{array}$ & $\begin{array}{c}\text { Expressão do } \\
\text { pensamento }\end{array}$ & $\begin{array}{c}\text { Instrumento de } \\
\text { comunicação }\end{array}$ & Lugar de interação \\
\hline $\begin{array}{c}\text { Concepçäo de } \\
\text { ensino }\end{array}$ & Mecanicista & Teleológica & Histórico-crítica \\
\hline $\begin{array}{c}\text { Objetivo do } \\
\text { ensino de } \\
\text { lingua materna }\end{array}$ & $\begin{array}{c}\text { Ensinar normas } \\
\text { para o bem falar } \\
\text { e para o bem } \\
\text { escrever }\end{array}$ & $\begin{array}{c}\text { Ensinar composições com } \\
\text { o fito de enviar mensagens } \\
\text { a um ouvinte/leitor }\end{array}$ & $\begin{array}{c}\text { Refletir acerca das } \\
\text { diferentes formas de } \\
\text { interagir na e pela } \\
\text { linguagem }\end{array}$ \\
\hline $\begin{array}{c}\text { Papel do } \\
\text { estudante }\end{array}$ & $\begin{array}{c}\text { Memorizar a } \\
\text { prescrição } \\
\text { gramatical }\end{array}$ & $\begin{array}{c}\text { Aprender a escrever } \\
\text { composiçôes }\end{array}$ & $\begin{array}{c}\text { Capacitar-se para } \\
\text { interagir nas diferentes } \\
\text { práticas de linguagem da } \\
\text { vida social }\end{array}$ \\
\hline $\begin{array}{c}\text { Papel do } \\
\text { professor }\end{array}$ & $\begin{array}{c}\text { Transmitir a } \\
\text { norma-padrão }\end{array}$ & $\begin{array}{c}\text { Ensinar a escrever } \\
\text { composições em } \\
\text { conformidade com as } \\
\text { sequências textuais }\end{array}$ & $\begin{array}{c}\text { Operacionalizar } \\
\text { atividades que façam } \\
\text { refletir sobre as diferentes } \\
\text { maneiras de utilizar a } \\
\text { linguagem como meio de } \\
\text { engajamento/participação } \\
\text { social }\end{array}$ \\
\hline
\end{tabular}

Fonte: Os autores.

Desse modo, ainda que se preze pela pluralidade de práticas pedagógicas na realidade escolar, os Parâmetros Curriculares Nacionais - PCN (1998) e a Base Nacional Comum Curricular - BNCC (2018), no que tange ao ensino de língua, coadunam com uma concepção voltada para a prática social, ou seja, a linguagem como lugar de interação. Preza-se por um ensino que leve o sujeito a refletir como a linguagem é a simbologia humana que medeia sua ação nas diferentes instituições sociais de que necessita participar.

$\mathrm{Na}$ formação de professores, defende Kleiman (2008), os cursos de licenciatura e as várias instâncias responsáveis pela formação docente continuada devem projetar essas orientações de documentos oficiais para a prática do professor, permitindo que ele, ao passo que (res)significa sua práxis, também transforme seu agir para conseguir refinar as habilidades interacionais dos estudantes.

Defendemos, com Andrade, Lima e Serra (2020a, 2020b), que as narrativas (auto)biográficas são materialidades discursivas que promovem a (res)significação e a (auto)(trans)formação do professor num projeto interacional em que o sujeito, ao mesmo tempo que seleciona fatos importantes (re)veladores de crenças sobre ensino, também reflete sobre sua prática e as consequências dela na vida prática. Para melhor entender como as narrativas propiciam a (auto)(trans)formação docente, empreendemos a discussão do tópico a seguir.

\section{AS NARRATIVAS DE VIDA COMO PRÁTICA (AUTO)(TRANS)FORMATIVA}

O movimento de biografização da vida (DELORY-MOMBERGER, 2008) está fortemente ligado às transformações tecnológicas e econômicas implementadas com a rapidez industrial a partir de 1970. Foi imposta outra cadeia de produção, exigindo que, individualmente, os sujeitos gerenciassem conhecimentos e trajetórias profissionais. À noção de competência é outorgada uma especialização, isto é, as ocupações profissionais são subjetivadas ao ponto de reconhecimento pessoal e "[...] progressivo do capital de saberes e de saber fazer, acumulado 


\section{$=$ TRAMA $=$}

ao longo da experiência e pela contextualização das ações de formações nos itinerários individuais" (DELORY-MOMBERGER, 2008, p. 87).

Aqui, definimos narrativa de vida tal como Vasconcelos (2005). Para ela, essas materialidades enunciativas diferenciam-se das histórias de vida na medida em que, enquanto nesta o narrador conta toda a sua vida, naquelas ele seleciona experiências que oportunizam catalisar suas crenças acerca de um saber específico. Ainda segundo Vasconcelos (2006, p. 63),

compreender a própria vida implica poder abraçá-la, cercá-la e reconstituí-la, pelo fato de enriquecerem seu percurso. Esses fatos unem os elementos mais distintos da vida do sujeito, separam fatos imbricados, enquanto loteiam e subdividem as opiniões mais rígidas. Contar a própria vida é também contar uma época histórica, um momento específico, um lugar, uma cultura formada de um coletivo de histórias.

Signorini (2006) afirma que, entre outras, as narrativas de vida são gêneros catalisadores. O adjetivo dado pela autora se inspira no processo químico da catálise, que significa a adição de uma substância que faz com que as moléculas reajam de maneira mais rápida. Assim, os gêneros catalisadores "favorecem o desencadeamento e a potencialização de ações e atitudes consideradas mais produtivas para o processo de formação, tanto do professor quanto de seus aprendizes" (SIGNORINI, 2006, p. 8).

Ao produzir uma narrativa de vida sobre, por exemplo, suas experiências com o ensino de língua materna, o professor, em formação inicial ou continuada, poderá fazer a seleção de vivências que lhe forem singulares e, por conseguinte, formativas (KLEIMAN, 2008). Ao fazer isso, ele não apenas narra fatos, mas também os avalia, ora aprovando, ora desaprovando ações, o que (re)vela saberes, crenças, concepções e representações que emergem da experiência.

Então, o processo formativo docente calcado na produção de narrativas permite que o professor revele e análise crenças que são, tanto no processo de elaboração narrativa quanto ao longo da própria formação, (re)dimensionadas, (res)significadas, o que, em maior ou menor medida, resvala em sua prática (KLEIMAN, 2008). A narrativa "se revela como um meio capaz de provocar o enfrentamento das representações individuais e coletivas" (RIBEIRO, 2008, p. 42), pois, na e pela narrativa de vida, os sujeitos (re)apresentam e (re)constroem sentimentos, sensações, representações, que são avaliadas e transformadas via narrativa.

O desdobramento disso, no que se refere à docência, se reflete nas escolhas metodológicas empreendidas na práxis, possivelmente cooperando para uma aula mais produtiva. Em função disso, Andrade, Lima e Serra (2020b) defendem que o processo de formação do professor de língua deve se pautar na produção de narrativas, pois a formação docente pensada com base na narração de si permite a emergência dos saberes do professor, de maneira que ele, como protagonista de sua práxis, poderá efetivar, alteritariamente, sua (auto)(trans)formação. Se a catálise é o processo que promove a rapidez de misturas químicas, os gêneros catalisadores concretizam uma formação docente que potencializa a reflexão sobre si e a transformação da práxis pedagógica. Como sintetizam Andrade, Lima e Serra (2020a, p. 461),

por meio da narração e da análise dos fatos vivenciados ao longo da vida referentes a um dado objeto de discurso, o sujeito empreende uma seleção minuciosa de experiências que deseja compartilhar, seja para delas se aproximar, seja para delas se afastar, o que produz uma ressignificação do seu agir, já que, ao longo desse complexo processo de enunciar uma narrativa da vida, o narrador 
mobiliza conhecimentos de diferentes ordens discursivas os quais permitem uma (re)orientação das concepções que se atualizam no discurso construído narrativamente e, consequentemente, das ações empreendidas em suas práxis pedagógicas.

Dessa forma, em concordância com essas perspectivas teórico-metodológicas, defendemos que gêneros narrativos, como relatos pessoais e fóruns de discussão, não são meras enunciações linguísticas de biografização de si, mas instâncias que promovem a (auto)(trans)formação docente, num viés interacional alteritário, dando voz ao professor, não Ihe impondo conhecimentos acadêmicos que, possivelmente, a seu ver, não se aplicam a sua prática escolar. Nesse escopo, a seguir, apresentamos as considerações metodológicas que viabilizaram a concretização do projeto analítico deste artigo.

\section{A ETNOSSOCIOLOGIA CLÍNICA COMO METODOLOGIA PARA COLETA E ANÁLISE DE NARRATIVAS DE VIDA}

Neste estudo, toma-se como princípio metodológico a etnossociologia clínica como elaborada por Andrade (2019). Essa perspectiva tem como objeto central as narrativas de vida, no viés dos estudos de caso.

Quadro 2: Princípios abalizadores da etnossociologia clínica

\begin{tabular}{|l|l|}
\hline \multicolumn{2}{|c|}{ ETNOSSOCIOLOGIA CLÍNICA } \\
\hline OBJETO CENTRAL DE COLETA E ANÁLISE & Narrativas de vida \\
\hline MÉTODO DE PROCEDIMENTO & Estudo de caso \\
\hline MÉTODO DE ABORDAGEM & Indução \\
\hline PRINCÍPIO DE COLETA & Postura clínica \\
\hline PRINCÍPIOS DE ANÁLISE & Ausculta e deontologia \\
\hline
\end{tabular}

Fonte: Os autores.

A abordagem diz respeito ao fato de o pesquisador evidenciar atenção à fala dos participantes de sua pesquisa, a fim de que estes percebam a importância do saber que emerge de sua experiência discursivamente narrativizada no processo de coleta de dados. Para Vasconcelos (2005), a abordagem clínica implica que a relação entre pesquisador e participante se torna horizontal, diferentemente dos métodos hipotético-dedutivos, que privilegiam uma verticalidade.

Figura 1: Relação verticalizada vs. Relação horizontalizada

Narratário

Fonte: Vasconcelos (2005, p. 32).

Quanto à análise, a etnossociologia clínica se baseia nos princípios de ausculta e deontologia. Como abordagem hermenêutica, aquele princípio se refere ao fato de o pesquisador apresentar o máximo de hipóteses interpretativas possibilitadas pelo discurso 


\section{$=$ TRAMA $=$}

narrativo elaborado, sem, contudo, superinterpretar as falas, o que se coaduna com a deontologia.

Valendo-se disso, o processo de coleta dos dados desta pesquisa aconteceu no Estágio em Oralidade, Escrita e Análise Linguística, atividade obrigatória do curso de LLP da UFC. A disciplina se caracteriza por ser um estágio de observação, momento em que os estudantes, professores em formação, vão a escolas com o fito de observar aulas e poder analisar como se dá a docência em um contexto real.

No período 2020.1, porém, a pandemia de Covid-19 se interpôs às atividades letivas. A disciplina de estágio sofreu com isso, pois não conseguimos escolas em que os estudantes pudessem observar aulas, em decorrência de os professores, naquele momento, ainda estarem organizando sua prática para o contexto remoto.

Como estudiosos interessados por narrativas de vida, percebemos que a escrita dessas materialidades discursivas configurar-se-ia como instância substituta da observação das aulas e da escrita de relatórios de estágio. A nosso ver, ao rememorar fatos acerca do próprio processo de aprendizagem ao longo da escolarização básica, os professores em formação poderiam, ao passo que narram, analisar como essas experiências influenciavam suas concepções sobre ensino de língua materna, aprovando-as ou não.

Por isso, ao invés de utilizar, como de costume, os relatórios como objeto de avaliação principal do estágio, priorizamos os fóruns, nos quais os estudantes narraram experiências, e a autoavaliação, nas quais eles tiveram a oportunidade de apresentar como o estágio promoveu (res)significação de crenças sobre o ensino de língua.

Os fóruns foram realizados em um grupo no Facebook. Optamos por essa plataforma por oportunizar a presença de alunos da pós-graduação em Linguística da UFC e Letras da URCA, que, naquele momento, cumpriam estágio de docência no ensino superior. Ainda, o Facebook possui recursos variados de interação, como reações, comentários, respostas, os quais promovem, a nosso ver, melhor comunicação entre os envolvidos na disciplina. O grupo foi configurado como privado, isto é, somente seus participantes tinham acesso ao que lá era postado, dando margem para que se sentissem num espaço acolhedor e de formação.

Neste estudo, interessa-nos o fórum de número 1 - a disciplina teve 5 fóruns. Nossa escolha por esse fórum se dá por, obviamente, ele ter acontecido logo no início das atividades letivas remotas, o que, a nosso ver, oportunizou uma narração das experiências menos articulada a vozes acadêmicas de autoridade com as quais, ao longo do estágio, em decorrência de leituras e de outras atividades, os alunos teriam contato.

Figura 2: Comando do fórum de discussão

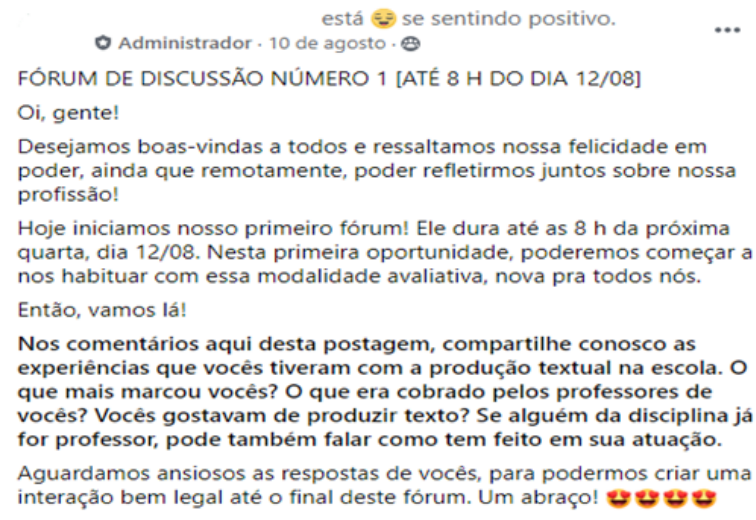

Fonte: Dados da pesquisa. 


\section{$=$ TRAMA $=$}

A autoavaliação, por seu turno, foi realizada por meio da plataforma Google Formulários. Nessa atividade, solicitamos que os alunos dissessem de que maneira o estágio havia promovido (res)significações sobre ensino de língua, transformando aquelas que possivelmente poderiam já possuir. Em nossa análise, interessa-nos o seguinte comando da autoavaliação.

Figura 2: Comando da autoavaliação

Que conhecimentos você adquiriu na disciplina? O que você, de fato, aprendeu? O que você aproveitará da disciplina? *

Fonte: Dados da pesquisa.

Para análise dos dados, primeiramente, entramos em contato com os estudantes da disciplina, enviando solicitação para utilizar suas narrativas para este estudo. Todos os 4 sujeitos que participaram desse primeiro fórum aceitaram o convite, materializando isso por meio da assinatura de termos de livre consentimento e esclarecimento, sob a ressalva de que teriam suas identidades protegidas. Para mantermos a identificação de todos os sujeitos da disciplina em sigilo, utilizamos o recurso de borrar as imagens que compuseram nosso corpus.

Por meio do recurso PrintScreen, construímos o corpus da pesquisa. Ao apresentarmos as figuras na análise, do lado esquerdo, ficará a interação dos fóruns no Facebook; do direito, a autoavaliação dos estudantes.

Segundo os pressupostos da etnossociologia clínica, a própria análise dos dados faz emergir as categorias de análise. O pesquisador que adota essa abordagem metodológica deve pré-analisar os dados a fim de elaborar as categorias que respondem a seus objetivos. Nessa perspectiva, procuramos aqui analisar as narrativas com base nas concepções de (ensino de) língua que os estudantes relatavam ter experenciado e como isso foi (res)significado, se é que foi, ao longo das discussões e das atividades do estágio. Nossa análise acontece a seguir.

\section{ANÁLISE DOS DADOS}

A primeira contribuição realizada no fórum narra o seguinte:

Figura 3: Narrativa de vida 1

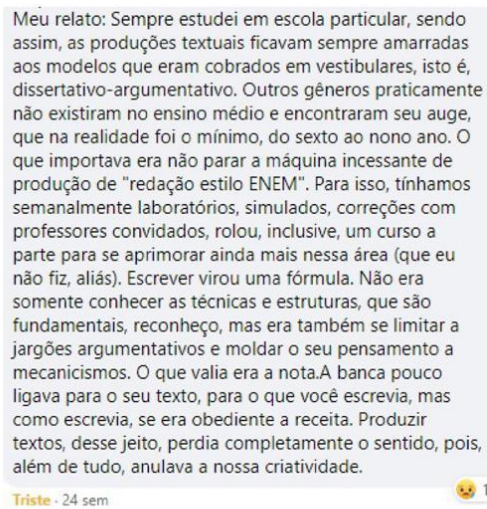

Trabalhar com gênero oral. Perceber a importância desse segmento $e$ como ele pode ser abordado em sala de aula.

Fonte: Dados da pesquisa.

Revista Trama | Volume 17 | Número 41 | Ano 2021 | p. 28-44 | e-ISSN 1981-4674 


\section{$=$ TRAMA $=$}

A primeira narrativa, assim como veremos nas demais, conta a questão da preparação para o Exame Nacional do Ensino Médio - Enem. É interessante que o narrador apresenta, inicialmente, que foi estudante da rede particular, articulando que, por isso, suas produções eram sempre voltadas para a aprendizagem do gênero redação. De fato, como sinalizam Freitas; Luna (2017), as escolas particulares exercem uma maior pressão nos estudantes para que, como evidencia a narrativa da Figura 3, aprendam uma fórmula capaz de Ihes fazer se apropriar de um molde elaborado com base na matriz de correção de redação para o Enem. Porém, é importante ressaltar que essa realidade não é observada somente em escolas particulares. Conforme o estudo de Freitas; Luna (2017), também a escola pública vem massificando seu ensino de produção textual para que os estudantes consigam se apropriar do texto dissertativo-argumentativo para o Enem.

Sem dúvida, apesar de não ser esse exatamente o objetivo maior da escolarização básica, é fato que o ingresso no ensino superior público é importante para que o estudante possa ascender socialmente. Por outro lado, como bem se coloca na narrativa ora analisada, a fixação por um formato único de produção textual resvala no entendimento de que "escrever é uma fórmula", pois, já que não era importante o que se escrevia, mas a obediência à "receita", a produção "perdia completamente o sentido". Além de narrar a experienciação do professor em formação com o processo de ensino e aprendizagem de produção textual, o narrador sinaliza que discorda de um ensino de escrita moldado, cujo propósito único seja uma nota.

Nesse sentido, embora suas experiências apontem para uma concepção de ensino calcada no entendimento de que linguagem é expressão do pensamento e instrumento de comunicação, o narrador, ao analisar sua experiência, permite inferir que gostaria de se afastar de concepções como essas, ou seja, de uma prática de ensino de produção que não conceba a língua como lugar de interação.

Schneuwly e Dolz (2004), por exemplo, apresentam a proposta de sequência didática para o ensino de línguas. A metodologia apresentada pelos autores, muito utilizada hoje em práticas escolares, privilegia o processo de aprendizagem da produção, favorecendo a reflexão do estudante sobre o que produz e sua autoria. Percebemos que a narração ora analisada critica o fato de que, ao privilegiar o atendimento a um molde, pensando numa nota, as produções textuais acabam retirando do estudante a capacidade de ser "criativo", o que, para nós, pode ser interpretado como a capacidade de ele ser autor de seu próprio texto. O produtor textual, nessa realidade, é apenas um reprodutor.

Embora tenha elaborado uma curta resposta em sua autoavaliação, podemos ver que esse processo de produção de narrativa corroborou uma importante ressignificação sobre o ensino de produção textual: os gêneros orais são também textos. Como vimos, na narrativa inicial do participante, ele apenas apresenta sua experiência com produção escrita, isso porque, certamente, apenas essa modalidade era objeto de ensino. Por outro lado, ao longo do estágio, analisamos, embasados nas orientações dos PCN (BRASIL, 1998) e da BNCC (BRASIL, 2018), que a oralidade é um eixo do ensino da aula de língua materna. O narrador fala, ainda, acerca da importância do ensino da oralidade e das metodologias que devem abalizar o processo de análise de textos orais. Em nossa experiência, discutimos a proposta de sequências didáticas (SCHNEWULY; DOLZ, 2004) para o ensino de produção textual em sala de aula, metodologia que prioriza o processo de aprendizagem, a reflexão sobre esse processo e a autoria, tudo isso sob o cenário de condições de produção. 


\section{$=T R A M A=$}

Figura 4: Narrativa de vida 2

\begin{abstract}
Meu $3^{\circ}$ ano foi em 2010, como faz 10 anos, não me lembro tão bem os detalhes. 0 que lembro é que fazíamos redações, no $1^{\circ}$ e $2^{\circ}$ ano do ensino médio, toda semana. No $1^{\circ}$ ano ainda fazíamos redações de outros gêneros, mas no meu segundo ano(2009), como o Enem seria aplicado oficialmente em 2010, começamos a fazer redações somente voltadas para a prova do Enem. Não lembro de ter laboratório de redação no meu $1^{\circ}$ e $2^{\circ}$ ano. $\mathrm{O}$ que lembro é que tínhamos uma das aulas de português voltadas para a discussão desse tema e que tínhamos que entregar toda terça-feira, por exemplo. No $3^{\circ}$ ano, tínhamos uma aula por semana voltada para a discussão do tema e, também, para como produzir uma redação, tanto dicas quanto regras gramaticais, etc. Além disso, tínhamos o laboratório de redação a noite(eu estudava de manhã). Nesse laboratório, tínhamos um tempo determinado para fazer a redação e alguns professores esperando para que fossemos corrigir com algum deles. Então, tínhamos a opinião desse professor sobre a nossa redação e sobre o que poderíamos melhorar. Como o já disse, o processo era meio robotizado mesmo. Eu já tinha o esquema pronto da minha redação, só ia adequando de acordo com o tema. O meu professor mesmo já aconselhava que tivéssemos um esquema meio que decorado mesmo, pois facilitaria na hora da produção na prova do Enem. Ah, dependendo do tema eu gostava de escrever sim, mas tinham temas que eram mais difíceis de escrever e que eu não curtia muito.

Triste 23 sem
Entendo, Autor
processo parecido com o seu, pois cursei o terceiro
ano em 2011. Como eu tinha mais facilidade com a
escrita, eu não era convidado a participar dos
laboratórios. Mesmo assim, algo que aproxima sua
narrativa da do ó o fato de que vocês
sempre escreveram para o professor. Eu também.
Mas nós sabemos que, na vida, não é bem assim.
Curtir $\cdot 23$ sem
\end{abstract}

\section{Que conhecimentos você adquiriu na disciplina? $O$ que você, de fato, aprendeu? $\mathrm{O}$ que você aproveitará da disciplina?}

Como pensar um plano de aula, como elaborar, como pensar e elaborar questões de acordo com determinado público-alvo. Tentar pensar atividades diferentes, tanto para uma aula mais interativa quanto para momentos imprevisíveis, como esse que estamos vivendo.

Fonte: Dados da pesquisa.

Na segunda narrativa, a narradora apresenta sua experiência relatando a robotização já referida pelo primeiro narrador. É preciso afirmar que o Enem, como destacam Freitas; Luna (2017), foi um importante empreendimento reorganizador da educação básica. Em função de ser a prova principal para o ingresso em universidades públicas e privadas de todo o país, o exame passou a ter suas competências e habilidades mais contempladas pelos profissionais da educação. No que se refere ao ensino de língua portuguesa, a prova prioriza pela concepção de linguagem como lugar de interação, tendo propiciado importantes ressignificações nas práticas de ensino de leitura, oralidade e análise linguística.

No que se refere ao ensino de produção escrita, a redação do Enem auxiliou também no entendimento que o texto escrito não é tão somente objeto de análise da correção ortográfica e gramatical. A redação do Enem, por também priorizar questões de textualidade, de condução argumentativa, de seleção de argumentos, de elaboração de propostas de intervenção, entre outras como objeto de avaliação, resvalou numa nova prática de ensino de produção textual escolar, preocupada também com o conteúdo que pelo texto se veicula (FREITAS; LUNA, 


\section{$=$ TRAMA $=$}

2017). Porém, essa prática, como vimos nas duas narrativas até agora apresentadas, teve como consequência uma focalização unicamente nesse gênero discursivo e um fornecimento de moldes que levem às notas mais altas no exame. Nesse sentido, embora tenha havido avanços, como colocam os narradores, concebe-se a língua como instrumento de comunicação, sendo a produção, como outrora, apenas evidência de uma nota, e não como um lugar de interação e de produção de sentidos entre interlocutores. Ao se apropriar da instrumentalização da grade de correção da redação do ENEM, houve um processo de mecanização do texto, que destitui a função de autor do estudante, vendo-o como reprodutor de fórmulas para chegar à nota máxima no exame.

Nesta narrativa, chama atenção, ainda, o reforço que a docente em formação dá ao seu registro ao convocar a narrativa feita anteriormente por outro colega. Este é um dos mecanismos da construção da experiência (JOSSO, 2004), pois tais comparações conservam e fortalecem o capital experiencial. Concernente a esse aspecto, e pela forma como as narrativas são coletadas, o compartilhamento de experiências pessoais com outros sujeitos na mesma condição formativa, pode ser, também, ferramenta de ampliação das próprias percepções. Por se tratar de um fórum virtual de discussão, os relatos, ao serem compartilhados, permitem a ativação de experiências dos interlocutores e, consequentemente, de novas (res)significações. Os registros narrativos escritos nos comentários servem de contexto para os outros componentes do grupo.

É interessante observar, também, nas duas narrativas apresentadas, que o estagiário de docência em ensino superior da disciplina curtiu ambos os textos com a reação triste. Isso leva a perceber que, como figura de autoridade na disciplina, no sentido de que o estagiário, além de cursar doutorado, também é professor da educação básica, sua reação direcionava para os participantes que seus relatos apresentavam uma experienciação ruim, isto é, que seu processo formativo, na atual conjuntura, elabora concepções de ensino de língua não apropriadas com o que é preconizado pela BNCC (BRASIL, 2018). Tal contribuição auxilia, a nosso ver, na ressignificação das concepções dos estagiários, uma vez que aponta que eles precisam se apropriar de outras maneiras de ensinar a língua que não sejam aquelas experienciadas.

Ao fazer sua autoavaliação, a narradora afirma agora se preocupar com questões concernentes à sua futura prática docente: produção de planos de aulas, análise de sua conjuntura escolar na elaboração de aulas, valorização dos conhecimentos dos alunos no processo de ensino e aprendizagem. Nesse sentido, a professora em formação deixa entender que a prática de estágio pautada na produção de narrativas de vida permite a (res)significação das experiências antes vividas por ela, tal como apresentaram Andrade, Lima e Serra (2020a, 2020b). O processo formativo propiciado ao longo do estágio congregou conhecimentos que Ihe possibilitaram perceber que o ensino de língua não deve se pautar somente na transmissão de moldes fixos de produção de texto, mas na construção de conhecimentos que levem ao apoderamento da linguagem nos contextos de interação. Para concretizar isso, segundo narra a professora em formação, é necessário refletir sobre a realidade em que se engaja, bem como produzir planos de aula que colaborem com essa prática. 


\section{$=T R A M A=$}

Figura 5: Narrativa de vida 3

Em relação a minhas experiências com produção textual na escola, lembro-me que a carta e a narração foram os principais gêneros trabalhados até $06^{\circ}$ ano. Durante esse período, enquanto a narração ficava restrita a aula de português, a carta aparecia como proposta nos livros de história, de geografia e de ciências. A partir do $7^{\circ}$ ano, produzi exclusivamente textos dissertativo-

argumentativos, pois, embora estudasse em aula outros gêneros, eles não eram cobrados em provas ou tarefas. Nas aulas de redação, não se cobrava a produção de textos em sala ou como tarefa de casa, e estudava-se sintaxe e norma padrão por meio de frases isoladas. Entretanto, o colégio oferecia um laboratório de redação, que ocorria duas vezes por semana no contraturno, como meio de melhorar a nota e preparar-se para o ENEM. No primeiro encontro do laboratório na semana, passava-se documentários para conhecer mais sobre o tema que seria proposto; no segundo encontro, corrigiase as redações feitas em casa sobre o tema e o professor dava "dicas" individuais para melhoria do texto. No $3^{\circ}$ ano, com o foco no ENEM, passei a produzir textos com indiferença, pois eles eram todos iguais. Importava-me apenas com a nota e usava uma única fórmula para todos os temas. Só voltei a gostar de produzir textos na faculdade. Ainda não tive experiências como professor, mas trabalhei na produção de livros didáticos. No trabalho, pude observar que os Anos Inicias e parte dos Anos Finais, devido a BNCC, passaram a trabalhar mais com textos multimodais ou multissemióticos, com auxilio de tecnologias, e que a narração perdeu bastante força.

Amei $\cdot 23 \mathrm{sem}$. Editado

0 Autor

Muito detalhado o seu relato! Meus parabéns! $́$ interessante porque realmente, ainda que leiamos outros gêneros na escola, nos últimos anos, a cobrança é mesmo a da dissertação-argumentativa. Mesmo assim, achei muito interessante essa metodologia de mostrar documentários para mobilizar conhecimentos prévios e, depois, incentivar a produção, dando um feedback para o processo refletir sobre sua escrita. Ao longo de nossas aulas, discutiremos um pouco sobre a importância de o autor refletir sobre o que escreve.

Curtir-23 sem

\section{Que conhecimentos você adquiriu na disciplina? $O$ que você, de fato, aprendeu? $\mathrm{O}$ que você aproveitará da disciplina?}

Considero planos de aulas e sequências didáticas importantes para o exercício docente, assim, a disciplina permitiu compreender e desenvolver maneiras de realizar ambos.

Fonte: Dados da pesquisa.

No texto em tela, o narrador apresenta suas diferentes experiências com o ensino de Língua Portuguesa. Inicialmente, aborda a questão de, até o $6^{\circ}$ ano, ter produzido diferentes gêneros, inclusive, em outras disciplinas, também eram solicitadas produções textuais escritas. Ao observar isso, podemos ver que, em sua experiência, o narrador põe em relevo toda uma conjuntura mais afeita a propostas sociointeracionais da língua, inclusive dando margem ao entendimento de que a produção textual não é tarefa tão somente de reflexão nas aulas de Língua Portuguesa, mas, já que todas as áreas se comunicam por textos, também das demais disciplinas.

A partir do $7^{\circ}$ ano, segundo relata o narrador, as produções textuais ficaram restritas à escrita de gêneros dissertativo-argumentativos, enquanto as aulas voltadas para o eixo de Revista Trama | Volume 17 | Número 41 | Ano 2021 | p. 28-44 | e-ISSN 1981-4674 


\section{$=$ TRAMA $=$}

leitura e de análise linguística priorizavam a diversidade de gêneros porque a sociedade se comunica. É interessante observar, a partir desse ponto, que, já no $7^{\circ}$ ano, as práticas de ensino se moldam aos interesses da grade de competências e habilidades para o Enem. Como o exame solicita a produção de um texto dissertativo-argumentativo, a escolarização básica trata esse texto como a necessidade única para engajamento pela escrita nas diferentes instituições sociais. Por outro lado, no que se refere às práticas de leitura e de análise linguística, assim como evidenciam as provas do Enem, prioriza-se pela diversidade de gêneros circulantes na vida social.

Além de isso revelar uma experienciação da linguagem voltada para a instrumentalização da comunicação, podemos perceber uma abordagem autônoma de letramento. Street (2014) afirma que as práticas de letramento são demarcadas pelas ideologias que organizam os sistemas de valores das instituições sociais. Por isso, ao ensinar leitura e escrita, segundo o autor, seria necessário analisar aspectos ideológicos, identitários, discursivos, culturais, históricos, relações de poder e autoria, papéis sociais, os quais organizam as maneiras de comunicação pela escrita em dada esfera de discurso.

Porém, conforme Street (2014), a escola se mantém, ainda, numa abordagem autônoma de letramento, que, segundo ele, destitui as práticas letradas de ideologia. Ou seja, nessa perspectiva, o letramento é entendido como uma diretriz aplicável a qualquer contexto discursivo. A norma-padrão, a produção dissertativo-argumentativa, a espetacularização e a estereotipação das variantes linguísticas, por exemplo, são as únicas habilidades a serem apre(e)ndidas pelos estudantes, caso queiram ser concebidos como letrados no âmbito da escolarização do letramento. Portanto, o letramento passa a ser percebido como uno, destituindo a língua de ideologia.

Como vemos na narrativa 3, o narrador aponta para esse processo de letramento autônomo, pois a preocupação do ensino é tão somente a de fazer com que os estudantes apre(e)ndam competências e habilidades necessárias à aprovação pelo Enem. Inclusive, ao falar sobre isso, o narrador afirma que sua preocupação única não era a interação via texto, mas a nota que tirava, ou seja, se sua aprendizagem se formatava aos moldes necessários para o êxito na prova.

Por outro lado, uma importante consideração apresentada pelo narrador é a troca de saberes entre ele e os professores no laboratório de redação. Essa prática permitia que estes apresentassem maneiras de aquele melhor conseguir se comunicar no molde específico elaborado conforme a grade de correção do Enem. Obviamente, isso concretiza uma prática de correção que dá relevo à troca de saberes entre aluno e professor, horizontalizando essa relação e destituindo a verticalização outrora realizada quando a este cabia a tarefa de apenas apontar erros ortográficos e sintáticos nas produções dos alunos.

Ao fazer sua autoavaliação, o sujeito apresenta como o estágio the proporcionou o entendimento de conceitos importantes para a prática docente. O plano de aula, já apresentado na narrativa anterior, prevê a escrita de um planejamento pensado para as necessidades de aprendizagem de uma turma, personalizando as práticas de ensino. Paralelamente, ao dar relevo ao conceito de sequência didática, o narrador afirma que "a disciplina permitiu compreender e desenvolver maneiras de realizar ambos", o que se coaduna com um interesse de o professor em formação, quando em exercício efetivo da docência, buscar empreender uma práxis mais voltada a concepções sociointeracionais da língua. 


\section{$=$ TRAMA $=$}

Figura 6: Narrativa de vida 4

Algo que me marcou bastante em relação à produção textual na escola foi que, para se adequar ao padrão do Enem,o colégio onde eu estudava trouxe uma mudança abrupta nas abordagens sobre produção textual. Nesse colégio em questão, eu estudei do oitavo ao terceiro ano, e me marcou bastante o fato de que, nos dois primeiros bimestres do oitavo ano, eram solicitadas produções de diversos gêneros, lembro de, nessa série, ter escrito, como tarefa de casa e como avaliação, contos, crônicas, cartas e até receita e todos esses gêneros eram bem trabalhados em sala e isso me interessava bastante. Porém, lembro que, quando foi se aproximando do final do ano, no oitavo ano, o professor falou que, como estávamos perto do nono ano, iríamos começar a focar no texto solicitado pelo Enem, o argumentativodissertativo, e explicou também que, a partir daquele momento, todas as nossas avaliações seriam para produzir textos nesse padrão. E assim foi até o meu terceiro ano, tínhamos aulas separadas só para redação, duas vezes na semana (no terceiro ano, eram mais aulas), mas todas elas focadas no modelo do Enem, outros gêneros apareciam esporadicamente, mas sem grande destaque. Toda semana, uma das aulas de redação era separada para produção textual em sala de aula e tínhamos avaliações parciais também, sempre com propostas de textos dissertativo-argumentativos e, como disse, outros gêneros eram muito pouco cobrados. Lembro até que meus colegas falava que não sabiam produzir outro texto, a não ser o dissertativoargumentativo. E, em mim, ficou essa lembrança de perceber essa mudança de abordagem e sentir falta dos textos que eram cobrados antes dessa fixação pelo Enem. E, com tudo isso, as aulas e as atividades referentes à redação se tornaram cansativas. No terceiro ano, havia o laboratório de redação, no turno oposto ao das aulas, e era opcional, ia quem queria, porque, além das redações do laboratório, havia as redações obrigatórias para serem entregues nas aulas mesmo. Eu só fui uma vez ao laboratório de redação, porque eu ouvia muitos relatos de alunos que choravam porque escutavam uma critica muito forte vinda de algum professor durante a correção da redação, tinha gente que ficava arrasada por zerar a redação ali na frente do professor e ouvir isso me deixava constrangido e com medo. $\dot{E}$ isso, infelizmente, um espaço da grade curricular que era para ser usado para ampliar a criatividade e a visão de mundo dos alunos acaba limitando e trazendo alguns traumas. Tenho, sim, também boas lembranças das aulas de redação, mas esse foco no Enem foi o que mais me marcou. Na época, eu já questionava isso e, hoje em dia, me questiono ainda mais e penso como essa limitação ao modelo do Enem é, em alguns pontos, prejudicial e que, estimulando os alunos a produzir outros gêneros, acaba que os estimula também a produzir otimos textos dissertativo-argumentativos.

Amei. 23 sem - Editado

\section{O Autor}

Everdade mesmo que, inicialmente, as escolas incentivam a criatividade via escrita, o que promove a autoria também. Ao longo da maturaçăo dos estudantes, ao invés de desenvolver essa escrita autoral, através de moldes, a escrita vai deixando de ter os traços de autoria.

Curtir-23 sem

\section{O que tornou a disciplina mais fácil e o que a tornou mais difícil para você?}

O que a tornou mais fácil foi a comunicação rápida e sempre acessivel com os estagiários e o que a tornou mais difícil foi o número de avaliações, o que eu achei que foi um pouco além do necessário, ainda mais nessa realidade que estamos vivendo. Sem dúvidas, essa disciplina me ajudou bastante em minha formação como professor, eu nunca tinha, por exemplo, elaborado uma proposta de produção textual e essa disciplina me deu essa oportunidade. Todos os conceitos e discussões vistos, sem dúvidas, me ajudarão bastante no meu futuro profissional. Fiz, com seriedade, todas as atividades propostas e refleti bastante em como elas estavam associadas com o fazer de um professor de Língua Portuguesa.

Fonte: Dados da pesquisa.

A narrativa 4 apresenta uma experiência bem parecida no que se refere à preparação para o Enem. Esse relato onipresente aponta para nós uma questão que deve ser, nos cursos de formação de professor, bastante refletida: sendo o Enem porta de entrada para o acesso à universidade, é preciso pensar em como dosar a preparação para a redação, considerando aspectos não prescritivos, que possam refinar a autoria do estudante. Ainda, deve haver uma 


\section{$=$ TRAMA $=$}

análise de como a escrita de outros gêneros é importante para construção do letramento num viés ideológico. Como podemos ver na narrativa ora analisada, embora no início do oitavo ano o estudante tenha produzido diferentes gêneros, inclusive relatando isso com certa nostalgia, demonstrando achar interessante esse trabalho analítico de diferentes gêneros, o participante diz que, no mesmo ano, começou-se o processo de preparação para a escrita da redação no molde estabelecido pela grade de avaliação do Enem. Esse protagonismo dado à dissertaçãoargumentativa, mesmo quando ainda não tinha uma formação universitária, já era questionado pelo narrador, uma vez que, a seu ver, isso limita a visão de mundo do estudante.

Nesse prisma, a reflexão propiciada pela narrativa de vida permite que o narrador problematize a concepção de ensino de língua que entende a linguagem como instrumento de comunicação, a qual emerge de sua experiência. Tal processo ocorre em função da catálise propiciada pela narrativa (SIGNORINI, 2006). Ainda, o estagiário reclama do momento de correção nos laboratórios, o qual, em sua realidade, era traumático para os estudantes, em função das críticas severas realizadas pelo corretor.

A autoavaliação do estagiário salienta o conceito de sequência didática, trabalhado na disciplina. Ao fazer isso, o enunciador revela sua percepção de um ensino mais voltado para análise da diversidade de gêneros circulantes na vida social, pautada num viés que permite o protagonismo do estudante e sua reflexão sobre a aprendizagem. Para o narrador, as reflexões propiciadas pela disciplina o acompanharão em sua práxis, pois elas empreenderam uma (res)significação que, desde jovem, quando ainda não estava em formação docente, o enunciador já fazia sobre a fixação de um ensino de produção escrita extremamente calcado em um molde fixo.

Outra questão que merece destaque no relato em tela é a menção de que o estágio foi o primeiro momento da licenciatura que engatilhou a escrita de propostas de produção textual, auxiliando sua formação docente. Na licenciatura em LLP da UFC, as disciplinas de estágio acontecem no último ano do curso; os períodos anteriores são reservados a disciplinas teóricas ${ }^{4}$. Obviamente, todo professor necessita de um aparato teórico para a práxis, porém a narrativa em tela revela que o curso, até então, não ofereceu espaços verdadeiramente formativos de articulação entre teoria e prática, processo tão caro à docência, como afirma Kleiman (2008).

Uma observação importante que fazemos em referência às narrativas analisadas é que, em nenhuma, os estagiários relatam experiências na educação básica com ensino de oralidade. Embora a primeira narrativa apresente que o estágio promoveu uma reflexão sobre isso, sua experiência como estudante também só priorizou a escrita. Tal silêncio, isto é, a não menção a experiências com oralidade, segundo Vasconcelos (2005), é também um achado de pesquisa. Isso revela que o ensino de oralidade é, ainda, coadjuvante na escolarização básica, para não dizer que sequer é objeto de análise.

Esse achado apresenta uma permanência do que já observaram Cavalcante e Melo (2007), ao dizer que a oralidade não é vista como interação que amplia o empoderamento dos sujeitos. Ao se depararem com a necessidade de ensinar a oralidade, os professores em formação, como percebemos na primeira narrativa analisada, revelam certa postura sensacional em relação à descoberta de que essa modalidade linguística é objeto de ensino.

Porém, a nosso ver, esse não é um problema somente da educação básica. Ao analisarmos o currículo do curso de LLP da UFC e suas ementas, nas disciplinas teóricas, não

\footnotetext{
${ }^{4}$ É possivel acessar o currículo em vigor no link:
} https://si3.ufc.br/sigaa/public/curso/curriculo.jsf;jsessionid=6A7CEBBCFDEAB9C46B9CC6558ECBA877. nod e23. Acesso em 23 jan. 2021. 


\section{$=$ TRAMA $=$}

há menção à oralidade, sendo o estágio aqui tratado, que ocorre no último ano do curso, o primeiro momento em que há possibilidade de se refletir sobre oralidade e ensino.

\section{CONCLUSÃO}

A análise revela que, ao se posicionar como professores em formação, os narradores não deixaram de lado vivências adquiridas quando alunos. As experiências vividas como discentes se manifestaram com um novo sentido, caracterizando-se como parte do saber que a formação docente lhes proporcionou.

Ademais, merece destaque a recorrência de temas nas narrativas. A redação do ENEM como gênero privilegiado nos últimos anos escolares, numa intenção puramente tecnicista, visando a melhor nota possível, é problemática há muito discutida. Nas narrativas, emerge reconhecimento da falta de pluralidade de práticas pedagógicas em relação ao tratamento do ensino, além de um abandono sistemático de outros gêneros. Dessa percepção, reflete-se, também, a falta de relevância que a oralidade recebe na programação. Essa é uma discussão importante se pensarmos que grande parte de nossas interações são feitas a partir da oralidade. Se a escola prepara para a vida em sociedade, privilegiar apenas a escrita pode prejudicar o desenvolvimento dessa habilidade.

Outra temática recorrente é da produção de planos de aula abalizados por sequências didáticas, o que coaduna com um desejo dos estagiários de construir metodologias mais reflexivas, processuais e horizontais no ensino de Língua Portuguesa, diferentemente daquilo que experienciaram quando alunos da educação básica.

Interessante notar que os pontos levantados pelos professores em formação são mediados pelas narrativas, fazendo da experiência anterior à formação acadêmica componente do saber - aqui entendido para além dos conteúdos previstos nos programas das disciplinas. Assim, a subjetividade dos narradores entrou no escopo formativo dos sujeitos, evidenciando que o vínculo com o próprio saber é uma forma de estar no mundo. Isso significa que nenhuma vivência subtrai de si a relação com o outro. Quando um sujeito examina fatos vividos, as (res)significações emergentes desse recorte incorporam percepções do momento presente.

Concebe-se que, no contexto pandêmico em que a observação de aulas ficou impossibilitada, as narrativas de vida, em substituição à observação e à escrita de relatórios, permitem que os narradores selecionem experiências com as quais concordam e/ou discordam, elaborando análise que evidencia seus desejos de efetivar uma prática diferente daquela experienciada.

\section{REFERÊNCIAS}

ANDRADE, F. R. da S. Autoconceitos de leitura erigidos a partir de narrativas de vida de professores alfabetizadores. 2019. 192 f. - Dissertação (Mestrado) - Universidade Federal do Ceará, Departamento de Letras Vernáculas, Programa de Pós-graduação em Linguística, Fortaleza, 2019.

ANDRADE, F. R. da S.; LIMA, P. S. R. de; SERRA, D. G. A ressignificação do ensino de leitura propiciada pela formação docente: um estudo de caso a partir de narrativas de vida. Fólio - Revista de Letras, v. 12, n. 1, p. 441-463, jan./jul. 2020.

ANDRADE, F. R. da S.; LIMA, P. S. R. de; SERRA, D. G. A narrativa de vida como construtora das concepções docentes de leitura: um estudo de casa. Letra Magna, v. 16, n. 25, p. 1-21, jan./jun. 2020. BRASIL. Ministério da Educação. Parâmetros Curriculares Nacionais: $3^{\circ}$ e $4^{\circ}$ ciclos do Ensino Fundamental: Língua Portuguesa. Brasília/DF: MEC/SEF, 1998.

BRASIL. Ministério da Educação. Base nacional comum curricular. Brasília/DF: MEC/SEF, 2018.

CAVALCANTE, M. C. B.; MELO, C. T. V. Gêneros orais na escola. In: SANTOS, C.F.; MENDONÇA, M.; CAVALCANTE, M. C. B. Diversidade Textual: os gêneros na sala de aula. Belo Horizonte: Autêntica; 2007. p. 89-102.

DELORY-MOMBERGER, C. Biografia e educação: figuras do indivíduo-projeto. Tradução: M. da Conceição Passeggi, J. G. da Silva Neto e Luís Passeggi. Natal: EDUFRN; São Paulo: Paulus, 2008. 


\section{$=\mathrm{T} R A M A=$}

FREITAS, L. P. de; LUNA, T. S. e. Concepções de texto e escrita nas propostas de produção textual do novo Enem. In: MARCUSCHI, B.; SIMÕES, T. (Org.) Avaliação de Língua Portuguesa no Novo Enem. São Paulo: UniAnchieta, 2017, p. 243-280.

GERALDI, J. W. Concepções de linguagem e ensino de português. In: GERALDI, J. W. (org.) O texto na sala de aula. São Paulo: Ática, 2011, p. 33-38.

JOSSO, M. C. Experiências de vida e formação. Tradução: José Cláudio e Júlia Ferreira. São Paulo: Cortez, 2004.

KLEIMAN, Â. (Org.). A formação do professor: perspectivas da lingüística aplicada. Campinas, SP: Mercado de Letras, 2008.

$\mathrm{KOCH}$, I. V. A inter-ação pela linguagem. 11. ed. São Paulo: Contexto, 2013.

RIBEIRO, P. B. O discurso docente (re)velado no gênero memorial. 2008. 293 f. Tese (Doutorado em Letras) - Programa de Pós-Graduação em Letras, Pontifícia Universidade Católica de Minas Gerais, Belo Horizonte, 2008.

SCHNEUWLY, B; DOLZ, J. Gêneros orais e escritos na escola. Tradução e organização de Roxane Rojo e Glaís Cordeiro. Campinas: Mercado de Letras, 2004.

SIGNORINI, I. Prefácio. In: SIGNORINI, I. (org.) Gêneros catalisadores, letramento e formação do professor. São Paulo: Parábola, 2006, p. 7-16.

SILVA, E. T. Concepções de leitura e suas consequências no ensino. Perspectiva, Florianópolis, v. 17, n. 31, p. 11-19, jan./jun. 1999.

STREET, B. V. Letramentos sociais: abordagens críticas do letramento no desenvolvimento, na etnografia e na educação. Tradução de Marcos Bagno. São Paulo: Parábola Editorial, 2014.

VASCONCELOS, S. M. F. Clínica do Discurso: a arte da escuta. Fortaleza: Premius, 2005.

VASCONCELOS, S. M. F. Professor: que história é essa? Revista Educação em Questão, Natal, v. 25, n. 11, p. 62-79, jan./abr. 2006.

VOLÓCHINOV, V. Marxismo e filosofia da linguagem. Tradução, notas e glossário de Sheila Grillo e Ekaterina Vólkova Américo. 2. ed. São Paulo: Editora 34, 2018. 